\title{
An essential role of Bmp4 in the atrioventricular septation of the mouse heart
}

\section{Kai Jiao, ${ }^{1,3}$ Holger Kulessa, ${ }^{2}$ Kevin Tompkins, ${ }^{1,3}$ Yingna Zhou, ${ }^{2}$ Lorene Batts, ${ }^{1,3} \mathrm{H}$. Scott Baldwin, ${ }^{3}$ and Brigid L.M. Hogan ${ }^{1,4,5}$}

\begin{abstract}
${ }^{1}$ Howard Hughes Medical Institute and ${ }^{2}$ Department of Cell and Developmental Biology, Vanderbilt University Medical Center, Nashville, Tennessee 37232, USA; ${ }^{3}$ Division of Pediatric Cardiology, Department of Pediatrics, Vanderbilt University Medical Center, Nashville, Tennessee 37232, USA
\end{abstract}

Proper septation and valvulogenesis during cardiogenesis depend on interactions between the myocardium and the endocardium. By combining use of a hypomorphic Bone morphogenetic protein 4 (Bmp4) allele with conditional gene inactivation, we here identify Bmp4 as a signal from the myocardium directly mediating atrioventricular septation. Defects in this process cause one of the most common human congenital heart abnormalities, atrioventricular canal defect (AVCD). The spectrum of defects obtained through altering Bmp4 expression in the myocardium recapitulates the range of AVCDs diagnosed in patients, thus providing a useful genetic model with AVCD as the primary defect.

Received June 24, 2003; revised version accepted August 5, 2003.

Congenital heart malformation is the most common human birth defect and the leading cause of death in the first year of life (Hoffman 1995). One of the most frequently diagnosed disorders is atrioventricular canal defect (AVCD), which accounts for $7.3 \%$ of all congenital heart abnormalities (Pierpont et al. 2000). During normal development, septation of the AV canal (AVC) is initiated with the formation of the inferior and superior endocardial cushions through epithelial-mesenchymaltransformation (EMT) by some endocardial cells invading into cardiac jelly, the extracellular matrix between the endocardium and myocardium (Nakajima et al. 2000; Markwald and Wessels 2001). Subsequent growth and fusion of the AV cushions produce the central mesenchymal mass, which further develops into the mature AV septum and valves through complex remodeling processes. The central mesenchymal mass also fuses with the atrial septum primum (ASP) and the inlet portion of the ventricular septum to prevent abnormal blood flow between chambers (Marino and Digilio 2000; Markwald and Wessels 2001). AVCD covers a spectrum of abnor-

[Keywords: Bmp4; atrioventricular septation; cardiogenesis] ${ }^{4}$ Present address: Department of Cell Biology, Duke University Medical Center, Box 3709, Durham, NC 27710, USA ${ }^{5}$ Corresponding author.

E-MAIL b.hogan@cellbio.duke.edu; FAX (919) 864-8592.

Article published online ahead of print. Article and publication date are at http://www.genesdev.org/cgi/doi/10.1101/gad.1124803. malities, from the partial form with defects in the lower part of the ASP to the complete form in which absence of the AV septum results in a single common AVC (Marino and Digilio 2000).

The complex cushion morphogenesis during AV septation depends both on signals released from the overlying myocardium and on proper responses of the endocardial and mesenchymal cells (Nakajima et al. 2000; Markwald and Wessels 2001). The molecular pathways for the initiation of cushion formation (EMT) have been studied extensively. In both chicken and mouse explant culture assays, transforming growth factor $\beta 2$ (TGF $\beta 2$ ) is able to replace the overlying myocardium to activate EMT, and inhibition of TGF $\beta 2$ activity blocks EMT (Boyer et al. 1999; Nakajima et al. 2000; Camenisch et al. 2002a). Consistent with these in vitro studies, TGF 2 2-deficient mice show defects in valvulogenesis (Bartram et al. 2001). In addition to the TGF $\beta$ signaling pathway, the Hyaluronic acid (Ha) synthase 2 (Has2)/ErbB2,ErbB3/Ras pathway has been recently shown to play essential roles in EMT (Camenisch et al. 2000, 2002b). Ha is a prominent component of cardiac jelly in embryonic day 9.5 (E9.5) embryos and its production depends on Has2. In addition to serving as a substrate for migration, $\mathrm{Ha}$ is responsible for phosphorylation of ErbB2 and ErbB3 through unknown mechanisms to activate the Ras pathway. Expression of dominant-negative Ras blocks EMT in wild-type embryonic hearts, suggesting that activation of the Ras pathway is required for EMT (Lakkis and Epstein 1998; Camenisch et al. 2000, 2002b).

Although knowledge about the onset of EMT is accumulating, little is known about mechanisms governing morphogenic events after cushions have formed. A recent study shows that myocardial-specific inactivation of a Bmp type I receptor gene, Alk3, causes abnormal AV cushion morphogenesis, although the similarity between the defects in these mice and human patients is not clearly defined (Gaussin et al. 2002; Schneider et al. 2003). Because the receptor gene is specifically deleted in muscle cells, the AV cushion defect in these mice is primarily caused by cardiomyocyte abnormalities, including increased apoptosis and reduced TGF 32 expression (Gaussin et al. 2002; Schneider et al. 2003). Other studies have also demonstrated a requirement for myocardial integrity for proper AV septation, including analysis of $\mathrm{Fog}^{-/-}$(Tevosian et al. 2000) and $\mathrm{Cx} 4 \mathrm{O}^{-1-}$; $\mathrm{Cx} 43^{+/-}$mutants (Kirchhoff et al. 2000). These results further strengthen the idea that communication between the myocardium and mesenchyme/endocardium is essential for normal morphogenesis even after cushions have formed. However, no signaling molecule from the myocardium that directly mediates later stages of AV septation has been identified. Resolution of this problem is key to understanding the molecular pathology of clinically observed AVCDs.

Bmp4 belongs to the TGF $\beta$ superfamily of cytokines, and has been implicated in numerous developmental processes (Hogan 1996; von Bubnoff and Cho 2001). The activity of Bmp4 is mediated through heterodimeric complexes of type I and type II serine/threonine kinase receptors (von Bubnoff and Cho 2001). Previous gene expression and in vitro explant studies suggested that Bmp4 is a key myocardial signal for activating EMT 


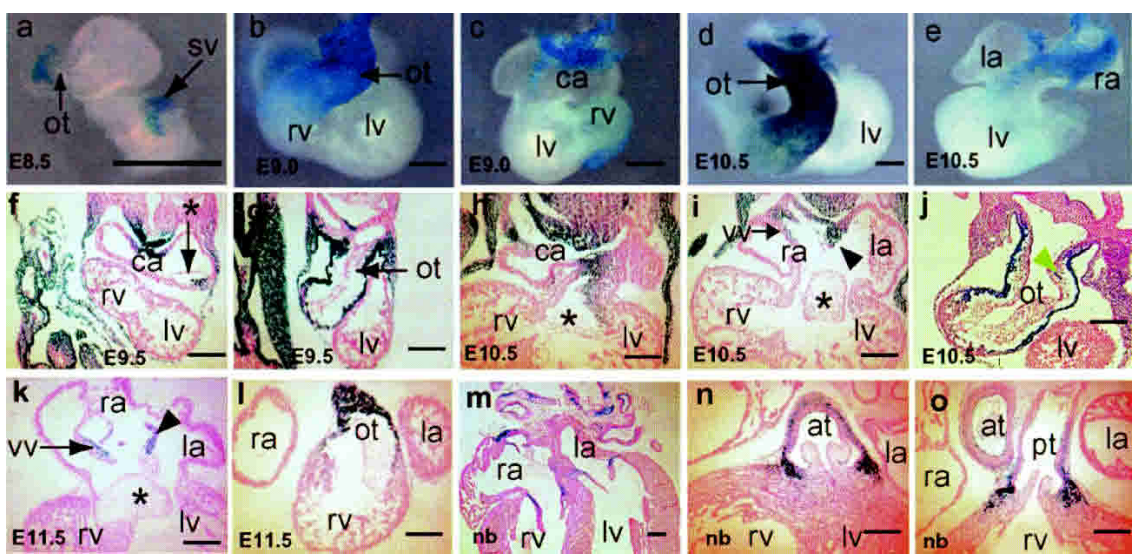

Figure 1. Expression of $B m p 4$ during cardiogenesis. $(a-e)$ Embryonic hearts of $B m p 4^{l a c Z /+}$ embryos on ICR background were collected at stages labeled in each panel, and were stained with X-gal. In the Bmp $4^{1 a c Z}$ allele, the lacZ reporter gene was knocked into the Bmp4 locus, and lacZ expression faithfully recapitulates endogenous Bmp4 transcription in $B m p 4^{1 a c Z /+}$ embryos. $(f-o)$ Transverse sections of whole embryos $(f-g)$ or frontal sections of hearts $(h-O)$ after whole-mount X-gal staining. All sections were counterstained with eosin. In addition to expression in the muscle layer of the OT $(g, j, l, n, o)$ in cardiomyocytes overlying the IEC $(f, h)$ and in muscular portions of ASP $(i, k)$ described in the text, positive signals were also detected in the mesenchyme of the truncus cushion at E10.5 (green arrowhead in $j)$, in the dorsal wall of the atrium $(f, h, i)$, in venous valves $(i, k)$, and in the annulus of mitral and tricuspid valves $(m)$. The Bmp4 expression pattern was confirmed with in situ hybridization analysis (data not shown). (at) Aorta trunk; (ca) common atrium; (la) left atrium; (lv) left ventricle; (nb) newborn; (ot) outflow tract; (pt) pulmonary trunk; (ra) right atrium; (rv) right ventricle; (vv) venous valve; $\left(^{\star}\right)$ AV endocardial cushions; (black arrow) atrial septum primum. Bars, $0.2 \mathrm{~mm}$.

(Markwald and Wessels 2001, and references therein). In this study, we circumvent the early lethality of $B m p 4$ null embryos (Lawson et al. 1999; Fujiwara et al. 2002) by combining use of a hypomorphic Bmp4 allele with a Cre/ loxp approach to manipulate levels of $B m p 4$ expression specifically in cardiomyocytes. Contrary to previous hypotheses, our results show that $B m p 4$ is dispensable for the initiation of cushion formation but is specifically required for proper AV septation after cushions have formed.

\section{Results and Discussion}

Despite extensive literature on the subject (Jones et al. 1991; Ikeda et al. 1996; Abdelwahid et al. 2001), the expression of $B m p 4$ during cardiogenesis has not been thoroughly characterized. We therefore examined embryos heterozygous for the $B m p 4^{\text {lacZ }}$ null reporter allele (Lawson et al. 1999) from E8.5 to birth (Fig. 1). Expression of Bmp4 in the outflow tract (OT) is detectable at E8.5 (Fig. 1a), and expression in the muscle layer of the OT and its derivatives (aorta/pulmonary trunk) is maintained until birth. In the inflow region, $B m p 4$ expression was first detected in the sinus venosus at E8.5 (Fig. 1a). At E9.0, $B m p 4$ signals are detected in the dorsal midline of the common atrium and weakly in the AVC. Significantly, these cells mark the position where formation of the ASP and inferior endocardial cushion (IEC) is initiated. Later, Bmp4 is expressed in cardiomyocytes overlying the IEC from E9.5 to E12.5 and in the muscular portion of the ASP from E10.5 to birth (Fig. 1; data not shown).

Expression of Bmp4 in cardiomyocytes in regions where septa are formed suggests that the gene plays critical roles during septation and valvulogenesis. To test this hypothesis, we applied a Cre/loxp system to specifically inactivate $\mathrm{Bmp} 4$ in cardiomyocytes. We first generated a transgenic line in which transcription of Cre recombinase is driven by the rat cardiac TroponinT (cTnT) promoter (Wang et al. 2000, 2001). By crossing these mice with ROSA26 reporter mice (Soriano 1999), we showed that cTnT-Cre induces recombination early in the cardiomyocyte lineage, starting from E7.5 and that recombination is restricted to the hearts until E10.5 (Fig. 2 ). High levels of recombination occur in the myocardium of all heart segments at E10.5 (Fig. 2d,e). Reverse transcriptase PCR (RT-PCR) analysis (Fig. 2f) confirmed that cTnT-Cre efficiently deletes $B m p 4$ from embryonic hearts between E9.5 and 10.5.

We previously constructed the floxed $B m p 4$ allele (Bmp4 $\left.4^{\text {loxp-lacZ }}\right)$, which has the advantage that recombination at the Bmp4 locus leads to expression of lacZ under the control of $B m p 4$ regulatory elements (Kulessa and Hogan 2002). Although Bmp4 $4^{10 x p-l a c Z / l o x p-l a c Z}$ mice develop normally, mice that are compound mutant for the $B m p 4^{\text {loxp-lacZ }}$ allele and the $B m p 4^{t m 1}$ null allele $\left(B m p 4^{\text {loxp-lacZ/tm1 }}\right)$ lack normal eyes and die between day 1 and day 7 after birth, indicating that $B m p 4^{\text {loxp-lac } Z}$ is a hypomorphic allele. To examine the potential cardiac defects caused by deficiency (but not absence) of Bmp4 expression in all cells, we examined $B m p 4^{l o x p-l a c z / t m 1}$ neonatal hearts histologically $(n=7)$. Figure $3 \mathrm{~d}$ reveals a severe ASP abnormality with normal AV and ventricular septa, resulting in an ostium primum atrial septation defect or a partial AVCD. In humans, this defect, unless corrected by surgery, will lead to excessive intra-atrial shunting, right ventricle overload, and, ultimately, pulmonary hypertension. To specifically delete $B m p 4$ in the cardiomyocytes, we first crossed cTnT-Cre; Bmp $4^{\text {loxp-lacz/+ }}$ mice with Bmp4loxp-lacz/loxp-lacz mice. The cTnT-Cre; Bmp4 $4^{\text {loxp-lacZ/loxp-lacz }}$ (Bmp4 $4^{\text {cre;loxp-lacZ/loxp-lacz) neonates }}$ $(n=5)$ are grossly normal, but also die perinataly, recapitulating a similar ASP defect seen in $B m p 4^{\text {loxp-lacz/tm1 }}$ mice (Fig. 3f).

We next crossed $c T n T$-Cre;Bmp4 $4^{+/ t m 1}$ mice with

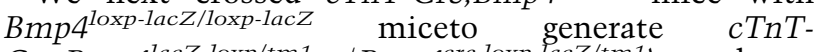
Cre;Bmp4 $4^{\text {lacZ-loxp/tm1 }} \quad\left(B m p 4^{\text {cre; } \text { loxp-lacZ/tm1 })}\right.$ embryos with only one floxed $B m p 4$ allele to be recombined. Complete deletion of $B m p 4$ in the heart would therefore 

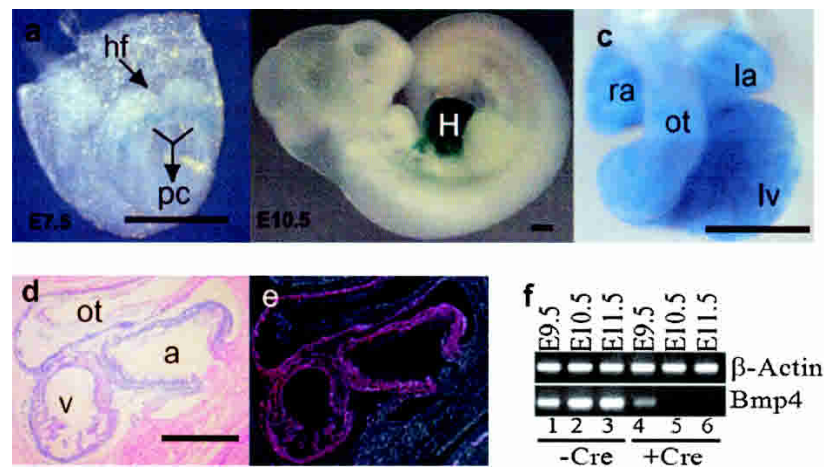

Figure 2. Recombination induced by cTnT-Cre. $(a, b)$ The $c \operatorname{Tn} T$ Cre;R26R ${ }^{+/-}$embryos at E7.5 $(a)$ and E10.5 $(b)$ were stained with $\mathrm{X}$-gal. (c) The heart dissected from the embryo in panel b. $(d, e)$ Sagittal sections of a $c T n T-C r e ; R 26 R^{+/-}$embryo at E10.5 stained with $\mathrm{X}$-gal. Panel $d$ represents the view in bright field and panel $e$ corresponds to the dark-field view. X-gal staining products appear pink, and are more easily detected in the dark field. Sections were counterstained with eosin. (f) Embryonic hearts were collected from

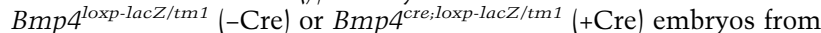
stages E9.5 to E11.5. RT-PCR analysis was performed to examine the expression of $B m p 4$, and $\beta$-Actin was used as a positive control. No PCR products were obtained if reverses transcriptase was omitted (data not shown). (H) Heart; (hf) head fold; (la) left atrium; (ot) outflow tract; (pc) precardiac crescent; (a) atrium; (ra) right atrium; (v) ventricle; (lv) left ventricle. Bars, $0.4 \mathrm{~mm}$.

be expected to be achieved more efficiently than in

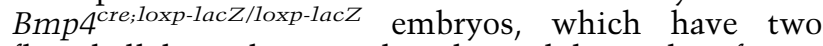
floxed alleles to be recombined. We did not identify any

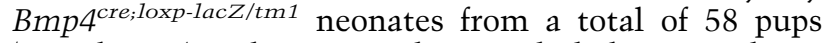
(nine litters), indicating embryonic lethality. We there- fore recovered $B m p 4^{\text {cre; } \text { loxp-lacZ/tm1 }}$ embryos $(n=10)$ at E15.5-E16.5, when septation is normally completed. These embryos have normal body and heart sizes, excluding a growth retardation defect. Histological examination revealed that all $B m p 4^{\text {cre;loxp-lacZ/tm } 1}$ embryonic hearts have the complete AVCD, a single AV junction with a common valve, which is identical to the phenotype of a human patient observed by ultrasound scan (Fig. $3 \mathrm{~m}, \mathrm{r}$ ). In the outflow regions, $80 \%(8 / 10)$ of the embryos display double-outlet-right-ventricle (Fig. 3p,q).

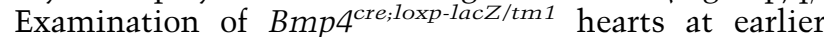
stages reveals that, although AV cushions are properly formed at E11.0 (Fig. $3 \mathrm{~g}, \mathrm{~h}$ ), their size is invariably reduced at E12.5 (Fig. 3i,j). The more severe malformation

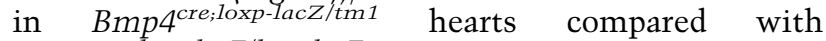
Bmp $4^{\text {cre; Ioxp-lacz/loxp-lacz }}$ hearts indicates that AV septation is very sensitive to the dosage of $B m p 4$ activity in vivo. The difference in $B m p 4$ expression in the localized region of the AVC of $B m p 4^{\text {cre;loxp-lacz/tm1 } 1}$ versus

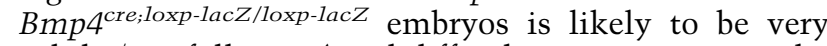
subtle (see following) and difficult to quantitate at the cellular level using current available techniques. Rather, the variable malformations summarized in Table 1 provide a sensitive biological readout of the different phenotype/genotype correlations.

Partial AVCD is caused by a deficiency in ASP formation, whereas the complete form is due to the underdevelopment of AV cushions (Marino and Digilio 2000; Pierpont et al. 2000). In humans, both forms are most commonly associated with Down syndrome (DS; Marino and Digilio 2000; Pierpont et al. 2000). Mice with trisomy 16 (Ts16), though serving as a classic model for studying DS, have several differences in cardiac pheno-
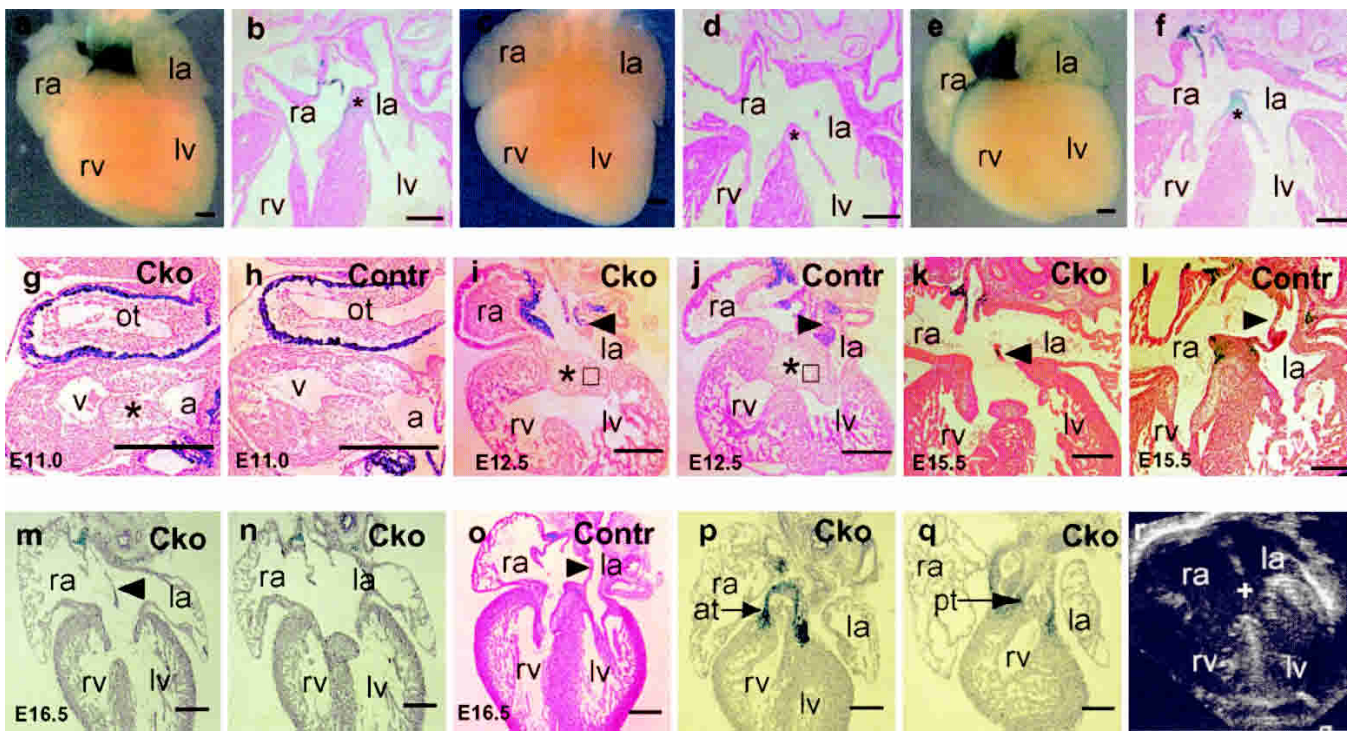

Figure 3. Dosage requirement of $B m p 4$ for AV septation. $(a-f)$ Neonatal hearts from $c T n T$-Cre $; B m p 4^{\text {loxp-lac } Z /+}(a, b), B m p 4^{\text {loxp-lac } / \text { tm } 1}(c, d)$, and Bmp4 $4^{\text {cre;loxp-laczlloxp-lacz }}(e, f)$ mice were stained with X-gal. cTnT-Cre;Bmp4 $4^{\text {loxp-lac } Z /+}$ mice are indistinguishable from wild-type mice (data not

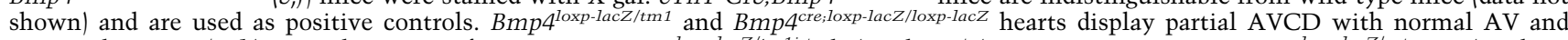

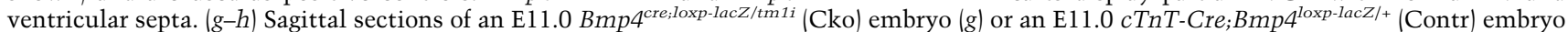

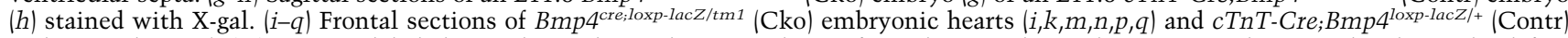
embryonic hearts $(j, 1,0)$ at stages labeled in each panel. Panels $n, p$, and $q$ are from the same heart shown in panel $m$. Panel $n$ shows the defect in ASP, which is not obvious in panel $\mathrm{m}$. Panels $p$ and $q$ show that both aorta and pulmonary trunk are connected to the right ventricle. $(r)$ An ultrasound scan of a heart from a human patient with the complete form of AVCD. The + indicates the common AVC. All sections were counterstained with eosin except sections of panels $m, n, p$, and $q$, which were stained with hematoxylin. (a) Atrium; (at) aorta trunk; (la) left atrium; (lv) left ventricle; (ot) outflow tract; $(\mathrm{pt})$ pulmonary trunk; $(\mathrm{ra})$ right atrium; $(\mathrm{rv})$ right ventricle; $(\mathrm{v})$ ventricle; $($ arrowhead) atrial septum primum; $\left(^{\star}\right)$ AV septum in panels $b, d$, and $f$, and AV cushions in panels $g, i$, and $j$. Bars, $0.2 \mathrm{~mm}$. 
Table 1. Summary of the cardiac malformations observed in Bmp4 mutants of different genotypes between E15.5 and PO

\begin{tabular}{llc}
\hline Genotype & Defects in OT & Defects in AVC \\
\hline Bmp4 $4^{\text {loxp-lacz/tm1 }}$ & None observed & ASD, partial AVCD \\
cTnT-Cre; & & \\
Bmp4 $4_{\text {loxp-lacz/loxp-lacz }}$ & None observed & ASD, partial AVCD \\
cTnT-Cre; & & \\
Bmp4 $4^{\text {cre } \text { loxp-lacz/tm1 }}$ & DORV $(80 \%)$ & Complete AVCD
\end{tabular}

(OT) Outflow tract; (AVC) atrioventricular canal; (ASD) atrial septal defect; (AVCD) AVC defect; (DORV) double outlet right ventricle.

type compared with patients with DS (Webb et al. 1997; Waller et al. 2000). All Ts16 mice show defects in their OTs, and $50 \%$ show unbalanced AV junction. In contrast, all Bmp4 $4^{\text {cre; } l o x p-l a c Z / t m 1}$ mice display a balanced AV junction between ventricles, and $20 \%$ of them show normal OT development, indicating that the etiology of AVCDs is separable from that of OT defects. Thus, $B m p 4^{\text {cre; } \text { loxp-lac } / \text { tm } 1}$ mice have cardiac defects that more closely resemble those of DS than do Ts16 mice. Because $B m p 4$ is on chromosome 14, it is likely that genetic interactions between $B m p 4$ and gene(s) on chromosome 21 are contributing factors in AVCD in DS patients.

The lack of defects in the initiation of cushion forma-

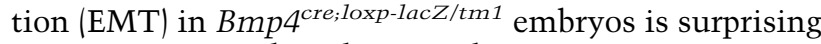
given in vitro studies showing that Bmps act synergistically with TGF $\beta$ in the initiation of EMT (Nakajima et al. 2000). This discrepancy may come from insufficient excision of Bmp4 before E9.5. To address this possibility, we took advantage of the fact that some $B m p 4^{\text {lacZ/lac } Z}$ embryos on ICR (Institute for Cancer Research) background survive to the $\sim 30$-somite stage with grossly normal hearts (Fig. 4a). Both the OT (data not shown) and AV cushions (Fig. 4b,c) in these hearts are normally initiated (extracellular matrix production and EMT) even when Bmp4 is completely deleted, supporting the conclusion that Bmp4 is dispensable for the initiation of cushion formation. Many other BMPs (BMP2, BMP5, BMP6, BMP7, BMP10) are expressed in the embryonic heart (Lyons et al. 1990, 1995; Dudley and Robertson 1997; Neuhaus et al. 1999) and may compensate for the loss of Bmp4. However, after cushions have formed, $B m p 4$ is uniquely required for the proper septation of the AVC.

Myocardial-specific inactivation of Alk3 causes malformation in the AV cushions due to increased myocyte apoptosis and down-regulation of TGF 32 expression in the myocardium surrounding the AVC (Gaussin et al.

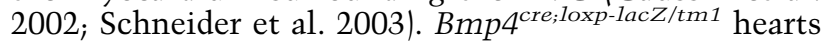
do not show any morphological defects, aberrant apoptosis, or abnormal proliferation in their myocardium (see following), suggesting that Bmp4 is dispensable for myocardial development. We further showed that TGFB2 expression is unaltered in $B m p 4^{\text {cre }}$; loxp-lacZ/tm1 hearts (Fig. $4 \mathrm{~d}, \mathrm{e})$, suggesting that the AVCD in Bmp4 $4^{\text {cre; loxp-lacZ/tm1 }}$ hearts is not due to impaired Bmp signaling in the myocardium. We directly tested whether alteration in cell proliferation and/or apoptosis in AV cushions contributes to the AVCD in Bmp $4^{\text {cre; } \text { loxp-lacZ/tm1 }}$ hearts. AntiKi67 staining showed that the cell proliferation rate in AV cushions, but not in other cardiac regions at E12.5, is reduced by $\sim 20 \%$ compared with controls (Fig. $4 \mathrm{f}-\mathrm{j}$ ). Al- though moderate, the significant growth reduction is sufficient to cause a dramatic cumulative effect over several generations of cell division. Consistent with this result, inactivation of Smad6 (a Bmp-specific nuclear inhibitor) causes hyperplasia of cardiac valves (Galvin et al. 2000). We did not observe enhanced apoptosis in

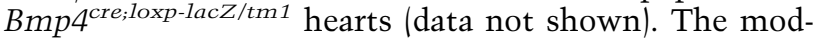
erate growth rate reduction of mesenchymal cells in AV cushions provides a potential mechanism accounting for the abnormal AV septum formation associated with normal valvulogenesis, as observed in the $B m p 4^{\text {cre } ; \text { loxp-lac Z/tm } 1}$ embryos and patients with AVCDs (like DS patients). A severe growth rate reduction in AV cushions is expected to block both the septation and valvulogenesis processes, whereas a moderate reduction may sufficiently block the AV septum formation but has little effect on valvulogenesis.

This study reveals Bmp4 as the only known signaling factor from the myocardium that directly regulates AV septation after cushions have formed. As summarized in Table 1, a modest reduction in $B m p 4$ gene expression (in $B m p 4^{\text {loxp-lacZ/tm1 }}$ or $B m p 4^{\text {cre; loxp-lacZ/loxp-lacZ mice) re- }}$ sults in the partial AVCD, and a more severe reduction $\left(B m p 4^{\text {cre; } \text { loxp-lacZ/tm1 })}\right.$ causes the complete form of AVCD. We thus provide a unique genetic model with AVCD as the primary defect.
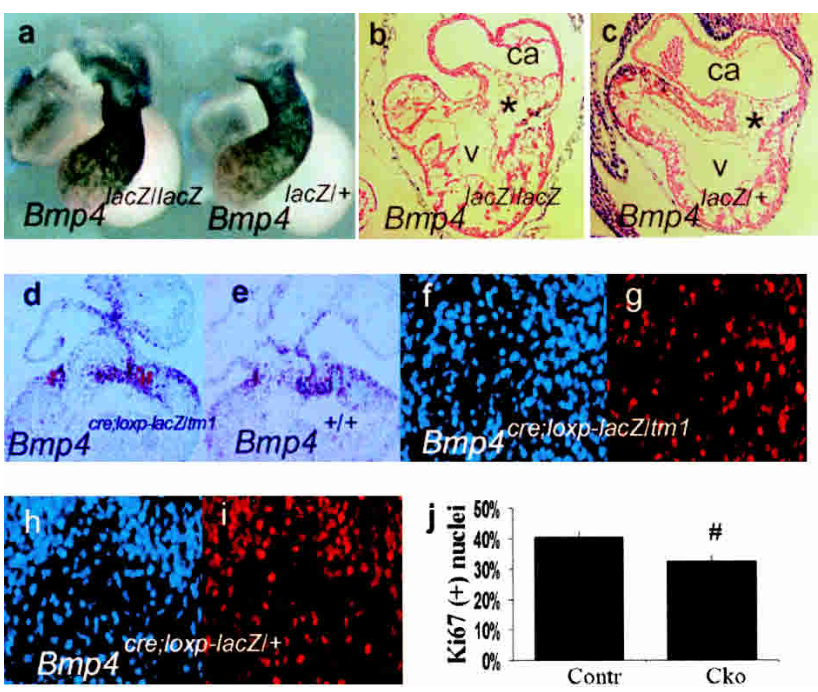

Figure 4. Phenotype of AV region of embryos of different $B m p 4$ genotypes. $(a, b, c)$ Normal formation of AV cushions in Bmp4 $4^{1 a c z / l a c Z}$ embryonic hearts. A heart from a Bmp4 $4^{\text {lacZ/lacZ }}$ embryo with 30 somites is grossly normal when compared with a $B m p 4^{1 a c Z /+}$ heart at the same stage $(a)$. Formation of AV cushions in a Bmp $4^{\text {lacZ/lacZ }}$ embryo $(b)$ parallels that of a $B m p 4^{1 a c Z /+}$ embryonic heart $(c) .(d, e)$ Results of section in situ hybridization using a TGF 2 2 probe. Expression of TGF $\beta 2$ in the AVC of a Bmp4 $4^{\text {cre;loxp-lacz/tm1 }}$ embryonic heart at E12.5 $(d)$ is not altered when compared with the results observed from a wild-type embryonic heart at the same stage (e). $(f-i)$ Frontal sections of Bmp4 $4^{\text {cre; loxp-lacz/tm1 }}(f, g)$ and cTnTCre;Bmp $4^{\text {loxp-lacz/+ }}(h, i)$ embryonic hearts at E12.5 are stained with DAPI to visualize the nuclei $(f, h)$ and with anti-Ki67 antibody to visualize proliferating cells $(g, i)$. Panels $f$ and $g$ correspond to the boxed regions of Figure 3c; panels $h$ and $i$ correspond to the boxed regions of Figure 3d. (j) The number of Ki67-positive nuclei as a percentage of total nuclei (mean \pm S.E.) of Bmp4 $4^{\text {cre;loxp-lacz/tm1 }}$ embryonic hearts (Cko) is reduced to about $80 \%$ of $c T n T$ -

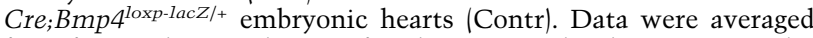
from four embryonic hearts of each strain, and at least 1500 nuclei were counted for each heart. (ca) Common atrium; $(v)$ ventricle; $\left.{ }^{\star}\right)$ AV cushions; (\#) $P=0.047<0.05$. 


\section{Materials and methods}

Mouse and embryo manipulations

All procedures are approved by the Institutional Animal Care and Use Committee at Vanderbilt University. Bmp4 $4^{\text {lacZ/+ }}$ mice on the (129/ SvEvxBlack Swiss) background have been outcrossed with ICR mice for at least 10 generations. Bmp $4^{\text {lacZ } / l a c Z}$ embryos were obtained by intercrossing ICR Bmp4 $4^{\text {IacZ/+ }}$ mice (Weaver et al. 1999). The nls-Cre-hGH cassette [a gift from Dr. M. Magnuson (Vanderbilt University Medical Center, Nashville, TN)] was fused with the rat cTnT promoter [Wang et al. 2000, 2001; a gift from Dr. J. Lin (University of Iowa, Iowa City, IA)], and the DNA construct was injected into the pronuclei of one cell $(\mathrm{B} 6 \mathrm{D} 2)_{\mathrm{F} 1}$ embryos. A total of five independent cTnT-Cre founders were obtained. The \#5 line, maintained by intercross with $(\mathrm{B} 6 \mathrm{D} 2)_{\mathrm{F} 1}$ mice, was selected because it induced the highest level of recombination, as determined by crossing with Rosa26R reporter mice, which express $\beta$-galactosidase only when recombination has been effected by Cre (Soriano 1999). Embryo dissection, sectioning, and X-gal staining were performed as described (Lawson et al. 1999). Section in situ hybridization was performed as described previously (Jiao et al. 2002) using a TGFß2 probe [a gift from Dr. H. Moses (Vanderbilt University Medical Center, Nashville, $\mathrm{TN})]$.

\section{Proliferation assay}

Immunostaining was performed using anti-Ki67 nuclear antigen (Novocastra Laboratories), following the manufacturer's instructions. A Texas red conjugated anti-rabbit body was used as the secondary antibody and slides were also stained with DAPI to visualize all nuclei.

\section{RT-PCR analysis}

RT-PCR analysis was performed as described previously (Jiao et al. 2002). The primer sequences for amplifying $B m p 4$ and $\beta$-Actin mRNAs will be provided on request.

\section{Acknowledgments}

We thank Drs. J. Lin, M. Magnuson, and H. Moses for providing regents; Dr. J. Barnett for suggestions on the project; and Dr. E. Myers for commenting on the manuscript. K.J. was an Associate and B.L.M.H. an Investigator of the Howard Hughes Medical Institute. This project is currently supported by the NIH grant (HL62177) to H.S.B.

The publication costs of this article were defrayed in part by payment of page charges. This article must therefore be hereby marked "advertisement" in accordance with 18 USC section 1734 solely to indicate this fact.

\section{References}

Abdelwahid, E., Rice, D., Pelliniemi, L.J., and Jokinen, E. 2001. Overlapping and differential localization of Bmp-2, Bmp-4, Msx-2 and apoptosis in the endocardial cushion and adjacent tissues of the developing mouse heart. Cell Tissue Res. 305: 67-78.

Bartram, U., Molin, D.G., Wisse, L.J., Mohamad, A., Sanford, L.P., Doetschman, T., Speer, C.P., Poelmann, R.E., and Gittenberger-de Groot, A.C. 2001. Double-outlet right ventricle and overriding tricuspid valve reflect disturbances of looping, myocardialization, endocardial cushion differentiation, and apoptosis in TGF- $\beta(2)$-knockout mice. Circulation 103: 2745-2752.

Boyer, A.S., Ayerinskas I.I., Vincent, E.B., McKinney, L.A., Weeks, D.L, and Runyan, R.B. 1999. TGFß2 and TGFß3 have separate and sequential activities during epithelial-mesenchymal cell transformation in the embryonic heart. Dev. Biol. 208: 530-545.

Camenisch, T.D., Spicer, A.P., Brehm-Gibson, T., Biesterfeldt, J., Augustine, M.L., Calabro Jr., A., Kubalak, S., Klewer, S.E., and McDonald, J.A. 2000. Disruption of hyaluronan synthase-2 abrogates normal cardiac morphogenesis and hyaluronan-mediated transformation of epithelium to mesenchyme. J. Clin. Invest. 106: 349-360.

Camenisch, T.D., Molin, D.G., Person, A., Runyan, R.B., Gittenberger-de Groot, A.C., McDonald, J.A., and Klewer, S.E. 2002a. Temporal and distinct TGF $\beta$ ligand requirements during mouse and avian endocardial cushion morphogenesis. Dev. Biol. 248: 170-181.

Camenisch, T.D., Schroeder, J.A., Bradley, J., Klewer, S.E., and McDonald, J.A. 2002b. Heart-valve mesenchyme formation is dependent on hyaluronan-augmented activation of ErbB2-ErbB3 receptors. Nat. Med. 8: 850-855.

Dudley, A.T. and Robertson, E.J. 1997. Overlapping expression domains of bone morphogenetic protein family members potentially account for limited tissue defects in BMP7 deficient embryos. Dev. Dyn. 208: 349-362.

Fujiwara, T., Dehart, D.B., Sulik, K.K., and Hogan, B.L. 2002. Distinct requirements for extra-embryonic and embryonic bone morphogenetic protein 4 in the formation of the node and primitive streak and coordination of left-right asymmetry in the mouse. Development 129: 4685-4696.

Galvin, K.M., Donovan, M.J., Lynch, C.A., Meyer, R.I., Paul, R.J., Lorenz, J.N., Fairchild-Huntress, V., Dixon, K.L., Dunmore, J.H., Gimbrone Jr., M.A., et al. 2000. A role for smad6 in development and homeostasis of the cardiovascular system. Nat. Genet. 24: 171-174.

Gaussin, V., Van de Putte, T., Mishina, Y., Hanks, M.C., Zwijsen, A., Huylebroeck, D., Behringer, R.R., and Schneider, M.D. 2002. Endocardial cushion and myocardial defects after cardiac myocyte-specific conditional deletion of the bone morphogenetic protein receptor ALK3. Proc. Natl. Acad. Sci. 99: 2878-2883.

Hoffman, J.I. 1995. Incidence of congenital heart disease: II. Prenatal incidence. Pediatr. Cardiol. 16: 155-165.

Hogan, B.L. 1996. Bone morphogenetic proteins: multifunctional regulators of vertebrate development. Genes \& Dev. 10: 1580-1594.

Ikeda, T., Takahashi, H., Suzuki, A., Ueno, N., Yokose, S., Yamaguchi, A., and Yoshiki, S. 1996. Cloning of rat type I receptor cDNA for bone morphogenetic protein-2 and bone morphogenetic protein-4, and the localization compared with that of the ligands. Dev. Dyn. 206: 318-329.

Jiao, K., Zhou, Y., and Hogan, B.L. 2002. Identification of mZnf8, a mouse Kruppel-like transcriptional repressor, as a novel nuclear interaction partner of Smad1. Mol. Cell. Biol. 22: 7633-7644.

Jones, C.M., Lyons, K.M., and Hogan, B.L. 1991. Involvement of Bone Morphogenetic Protein-4 (BMP-4) and Vgr-1 in morphogenesis and neurogenesis in the mouse. Development 111: 531-542.

Kirchhoff, S., Kim, J.S., Hagendorff, A., Thonnissen, E., Kruger, O., Lamers, W.H., and Willecke, K. 2000. Abnormal cardiac conduction and morphogenesis in connexin 40 and connexin 43 double-deficient mice. Circ. Res. 87: 399-405.

Kulessa, H. and Hogan, B.L. 2002. Generation of a loxP flanked bmp4 ${ }^{\text {loxP-lacz }}$ allele marked by conditional lacZ expression. Genesis 32: 66-68.

Lakkis, M.M. and Epstein, J.A. 1998. Neurofibromin modulation of ras activity is required for normal endocardial-mesenchymal transformation in the developing heart. Development 125: 4359-4367.

Lawson, K.A., Dunn, N.R., Roelen, B.A., Zeinstra, L.M., Davis, A.M., Wright, C.V., Korving, J.P., and Hogan, B.L. 1999. Bmp4 is required for the generation of primordial germ cells in the mouse embryo. Genes \& Dev. 13: 424-436.

Lyons, K.M., Pelton, R.W., and Hogan, B.L. 1990. Organogenesis and pattern formation in the mouse: RNA distribution patterns suggest a role for bone morphogenetic protein-2A (BMP-2A). Development 109: $833-844$.

Lyons, K.M., Hogan, B.L., and Robertson, E.J. 1995. Colocalization of BMP 7 and BMP 2 RNAs suggests that these factors cooperatively mediate tissue interactions during murine development. Mech. Dev. 50: 71-83.

Marino, B. and Digilio, M.C. 2000. Congenital heart disease and genetic syndromes: Specific correlation between cardiac phenotype and genotype. Cardiovasc. Pathol. 9: 303-315.

Markwald, R.R. and Wessels, A. 2001. Overview of heart development. In Formation of the heart and its regulation (eds. R.J. Tomanek and R.B. Runyan), pp. 1-22. Birkhauser, Boston.

Nakaiima, Y., Yamagishi, T., Hokari, S., and Nakamura, H. 2000. Mechanisms involved in valvuloseptal endocardial cushion formation in early cardiogenesis: Roles of transforming growth factor (TGF)- $\beta$ and bone morphogenetic protein (BMP). Anat. Rec. 258: 119-127.

Neuhaus, H., Rosen, V., and Thies, R.S. 1999. Heart specific expression of mouse BMP-10 a novel member of the TGF- $\beta$ superfamily. Mech. Dev. 80: 181-184.

Pierpont, M.E., Markwald, R.R., and Lin, A.E. 2000. Genetic aspects of atrioventricular septal defects. Am. J. Med. Genet. 97: 289-296.

Schneider, M.D., Gaussin, V., and Lyons, K.M. 2003. Tempting fate: BMP signals for cardiac morphogenesis. Cytokine Growth Factor Rev. 14: $1-4$. 
Soriano, P. 1999. Generalized lacZ expression with the ROSA26 Cre reporter strain. Nat. Genet. 21: 70-71.

Tevosian, S.G., Deconinck, A.E., Tanaka, M., Schinke, M., Litovsky, S.H., Izumo, S., Fujiwara, Y., and Orkin, S.H. 2000. FOG-2, a cofactor for GATA transcription factors, is essential for heart morphogenesis and development of coronary vessels from epicardium. Cell 101: 729739.

von Bubnoff, A. and Cho, K.W. 2001. Intracellular BMP signaling regulation in vertebrates: Pathway or network? Dev. Biol. 239: 1-14.

Waller III, B.R., McQuinn, T., Phelps, A.L., Markwald, R.R., Lo, C.W., Thompson, R.P., and Wessels, A. 2000. Conotruncal anomalies in the trisomy 16 mouse: An immunohistochemical analysis with emphasis on the involvement of the neural crest. Anat. Rec. 260: 279-293.

Wang, Q., Sigmund, C.D., and Lin, J.J. 2000. Identification of cis elements in the cardiac troponin $\mathrm{T}$ gene conferring specific expression in cardiac muscle of transgenic mice. Circ. Res. 86: 478-484.

Wang, Q., Reiter, R.S., Huang, Q.Q., Jin, J.P., and Lin, J.J. 2001. Comparative studies on the expression patterns of three troponin $\mathrm{T}$ genes during mouse development. Anat. Rec. 263: 72-84.

Weaver, M., Yingling, J.M., Dunn, N.R., Bellusci, S., and Hogan, B.L. 1999. Bmp signaling regulates proximal-distal differentiation of endoderm in mouse lung development. Development 126: 4005-4015.

Webb, S., Brown, N.A., and Anderson, R.H. 1997. Cardiac morphology at late fetal stages in the mouse with trisomy 16: Consequences for different formation of the atrioventricular junction when compared to humans with trisomy 21. Cardiovasc. Res. 34: 515-524. 


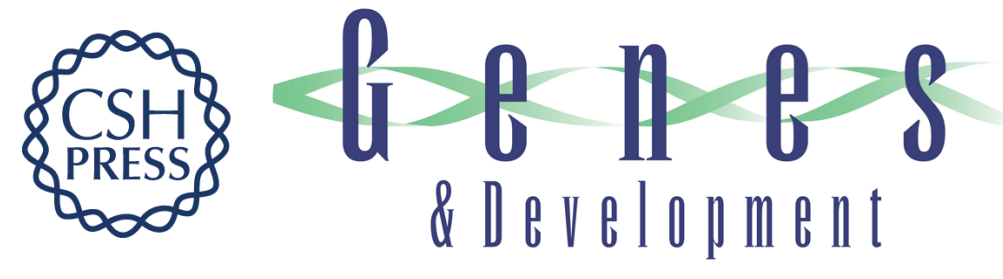

\section{An essential role of Bmp4 in the atrioventricular septation of the mouse heart}

Kai Jiao, Holger Kulessa, Kevin Tompkins, et al.

Genes Dev. 2003, 17:

Access the most recent version at doi:10.1101/gad.1124803

References This article cites 33 articles, 11 of which can be accessed free at: http://genesdev.cshlp.org/content/17/19/2362.full.html\#ref-list-1

License

Email Alerting Receive free email alerts when new articles cite this article - sign up in the box at the top Service right corner of the article or click here.

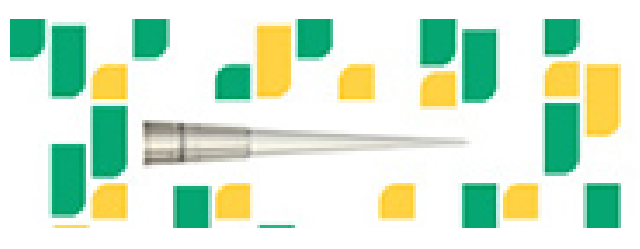

Focused on your science. 